\title{
Innovative and smart city: A theoretical study of adaptive solutions for sustainable solar urban districts
}

\author{
Jingxuan Zhang ${ }^{1,2, *}$, Chengwu Wang ${ }^{1,2}$, and Xiaohui Chen ${ }^{1}$ \\ ${ }^{1}$ SW Petroleum University, Xindu street 8, 610500, Chengdu, China \\ ${ }^{2}$ Boya Strategy in Chengdu area, Huanhua North Road 20, 61000, Chengdu, China
}

\begin{abstract}
This paper is a theoretical study of governing solar urban districts using the smart city system. It first presents the major theme of the sustainable urban future, points out the position of the solar energy in urban sustainable development. Then it presents the opportunities and challenges of the solar energy system, states that the innovation of technology from both the soft side and the hard side are the key points for governing the solar urban districts. The paper also shows the relationship between innovation, economies, and social sustainable development. Finally, the paper presents the smart city system as an innovative system. It needs to govern the solar urban district from all aspects (including but not limited to public services, city administration, and management, economy, pro-business environment, built environment and city infrastructure, natural environment and ecological sustainability). The lifecycle thinking and the GUUD model can be used to analyse and monitor the system. However, managing those fragment elements is not that simple. One of the challenges of integrating a smart city system is to build a connection between fragmental elements and make individual islands communicate with each other in order to achieve common goals.
\end{abstract}

\section{Introduction}

The solar energy system as one of the fast-growing clean energy systems, its development has significate meaning to climate change. However, building a sustainable solar urban district requires consideration from multidimensional aspects from the different levels. It is important to understand the position of the solar urban district in the large context of sustainable development, try to develop an innovative, smart and integrated solution (a framework) that governs the solar urban district from all aspects.

\section{The major theme of sustainable urban future}

In the second half of 20th century, an urban sprawl phenomenon with all the negative effects, such as increasing car-dependency for mobility, spending time daily on trips home-work, reduction of agriculture areas, the degradation of the landscape, reduction of air quality and higher energy consumption was led by urban development ${ }^{[1]}$.

Nowadays, the urban population seems to be a focus of urban development since more than half of the population is living in the city. It is expected that by the year $2050,70 \%$ of the world population will live in urban areas due to the urbanization ${ }^{[2]}$. However, in Europe, things become different. Amado \& Poggi states that the urban areas expanded rapidly while the population grows slowly. The ratio of population growth is still decreasing. It states that "such urban growth and effective expansion of cities has no support on a coherent urban model that has the capacity to prudently predicting the impacts of urbanization" [1].

These rapid and variable changes of urban development encourage cities all over the world to seeking new solutions to both old and new problems ${ }^{[2]}$. Sustainable development of the urban future is always a hot topic. It is becoming an important focus globally [3]. Nowadays, there are different models appeared to support multidisciplinary, multidimensional principles and requirements of urban sustainable development ${ }^{[1]}$.

When talking about sustainable development, in 1987, Brundtland Report gave a commonly accepted definition of sustainable development, stating that sustainable development is a development that meets the needs of the present without compromising the ability of future generations to meet their own needs ${ }^{[4]}$. According to the 2030 Agenda for sustainable development, "sustainable cities and communities" is one of the seventeen goals ${ }^{[3]}$.

Han et al. presented three major themes of the sustainable urban future in the context of highly industrialized regions: a low carbon society, cities in the context of an aging population and revitalization of the urban-rural fringe. In order to achieve a low carbon society, new technologies and systems need to be applied in the city. In order to adapt to an aging society, a compact city is seen as a solution. In order to enhance the urban-rural fringe, an eco-industries system is

\footnotetext{
* Corresponding author: jing.xuan.zhang@hotmail.com
} 
proposed. This study focuses on to build a low carbon society. According to the Fig. 1, the solar power as a renewable energy is a solution for low carbon society and urban-rural fringe ${ }^{[4]}$.

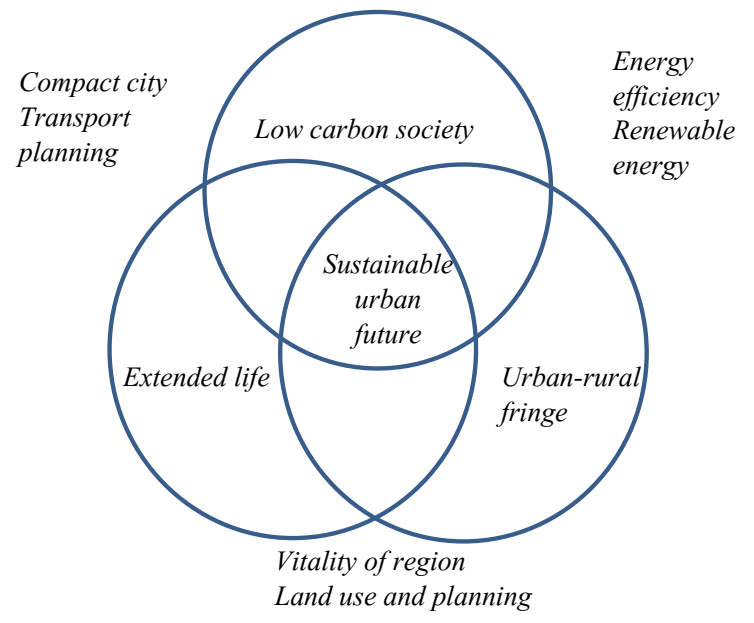

Fig. 1. Three major focuses among multiple themes concerning a sustainable urban future. A dapted from Han et al., 2012 [4]

\section{The solar power, opportunities, and challenges}

The phenomenon of the globalization is leading to an unsustainable path. Greenhouse-gas emission that is related to climate change is one of the most significant development issues of the future of human activities, ecosystems, and economies ${ }^{[5]}$

The solar power as one of the clean energy for reducing future greenhouse gas emissions is fastergrowing. There is a rapid growth with a $35 \%$ increase in solar power generation in 2015. However, the share of total global power is $1.7 \%$ which is still low. One thing that is worth to mention is that the share has doubled in the past three years. It is contributing nearly $20 \%$ of the growth of global power in 2017. The largest increments in 2017 were recorded in China. Together with the US, these two countries occupied two-thirds of the growth in global solar capacity. Japan is the third and Germany is now in fourth for the growth of global solar capacity ${ }^{[6]}$.

Even though the future of solar power seems to be bright and positive, there are still challenges in the way of promoting commercial solar power. Take Sweden as an example. Even though with a subsidy of $35 \%$ of the investment costs, discounted in 25 years, solar panels for electricity are still not profitable in Sweden for houses. In theory, the price of electricity needs to rise $30 \%$ to make the systems profitable with a kept subsidy of $35 \%$. Without the subsidy, the rise will be $95 \%{ }^{[7]}$.

It is clear that the solar energy system is facing challenges on both the soft side (such as economic and social challenges) and the hard side (such as technical challenges). Since the technology cannot stand long, it needs to be understood in the context of social, environmental, economic, and cultural progress in cities ${ }^{[2]}$. The implementation and management of solar power through urban planning can play a strategic role in improving the energy efficiency of the cities ${ }^{[5]}$. There is a need of innovated supportive system regarding not only technology itself but also a framework to govern the technology.

\section{Innovative solutions for governing the in urban districts}

Innovation plays an important role in sustainable development. It is mentioned before that the complex dynamics quality of the urban sustainable development requires new and innovative solutions ${ }^{[2]}$. It is important for nations to focus on innovation. The smart city system seems to be an innovative solution to govern the urban districts. However, its wide-range and complex dimensions are not easy to analyse. Finding a practical way to integrate the smart city system is crucial.

\subsection{Economic development driven by innovation drives social sustainable development}

The traditional and commonly accepted model that is governing sustainable development is the "three pillar model". In this model, social, ecological and economic are the three pillars to support sustainable development. This model is widely adopted at the legislative level.

However, according to Rockström, the "three-pillar model" cannot meet the challenges of the Anthropocene since the framework separated social, ecological, and economic goals and led to a fragmented approach. It failed to recognize that the three elements are actually interacting with each other. Thus, a new concept has been brought up (Fig. 2). In this concept, the economy is seen as a means to achieving social goals and generating prosperity within the limits of the Earth. In order to establish a sustainable economic growth, it requires the collective effort of nations, businesses, citizens, and institutions ${ }^{[8]}$. 


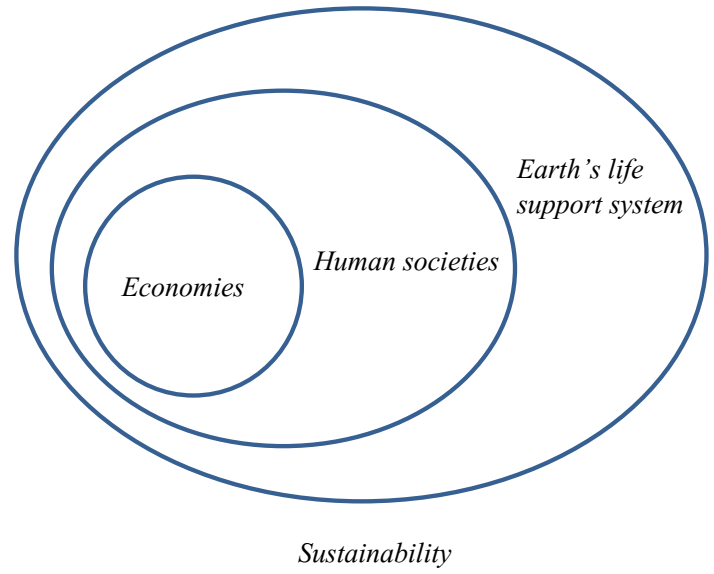

Fig. 2. Sustainable development paradigm for the Anthropocene, Rockström, 2015 ${ }^{[8]}$

In order to drive economic growth, in 2013, EU published National/ regional innovation strategies for smart specialization to implement the "Cohesion Policy" and Europe 2020" agenda [9]. It is to govern the EU to "become a mart, sustainable and inclusive economy". It focuses on economic development and covers five important things:

-Focus on knowledge-based development, provided policy support.

-Build on each country's strengths to ignite the excellence.

-Support practice-based new technology.

-Stakeholders' involvement to encourage innovation.

-Evidence-based monitory and evaluation system ${ }^{[9]}$.

There are other principles that are added to the smart specialization. Firstly, economic development is driven by knowledge and innovation. However, the economic regeneration, in the long run, is hard to plan. Secondly, it enchases the different quality of different EU regions, it is vital to analysis each region. Thirdly, the bottom-up approach is embraced by the perspective of economic growth. Fourthly, the policy is demand-oriented and is driven by local need ${ }^{[10]}$.

\subsection{An innovative solution of governing the urban district: the smart city}

When talking about the smart city, the use of information and communication technologies (ICTs) is always the key topic ${ }^{[2]}$. The ICT application is considered to be an innovative and integrated holistic approach to manage complex issues that are related to a low-carbon smart urban city. It can be used in areas such as transport, landuse planning, energy, water, and waste management ${ }^{[11]}$.

However, there is an increase of scholars and practitioners argue that smart cities are more than the use and development of ICTs in local government. GilGarcia et al. argue that the smartness is a public sector innovation in an urban context. When it comes to the analysis of cities, multidimensional concepts and components need to be considered. Those components include public services, city administration and management, policies and other institutional arrangements, governance and collaboration, human capital and creativity, knowledge economy and probusiness environment, built environment and city infrastructure, natural environment and ecological sustainability, ICT and other technologies, and data and information [2]. In another word, a comprehensive innovation policy should guide a city to become smart. Technology should be analysed under the context of a city, organizational, and policy. Furthermore, there is also a process perspective that is at a more operation level can be used to help to analyse the smartness of the city.

The lifecycle thinking gives a more practical and systematic way to analyse the multidimensional components. It is originally a scientific approach of the Sustainable Consumption Production based on large numbers of environmental policies and business decision ${ }^{[12]}$. However, the idea of lifecycle thinking is adapted in many places. For example, the Handbook for product social impact assessment provided a set of guidelines to measure the social impact of the production of a product [13].

A workflow perspective that is similar to the LCA thinking is used in the GUUD model to managing the integration of solar energy. It is a Geographical Urban Units Delimitation model that turns the city into different cellular units with different solar power stations that behaviour like atoms. It divides the city based on four delimitation criteria: construction timeline, population density, urban morphologies, and land-use patterns. The data and inputs of the model are collected based on the workflow that combines GIS with parametric modelling and solar dynamic analysis ${ }^{[5]}$.

The process perspective gives a chance for easy grouping and easy measuring of the fragmental elements of the smart city. However, managing those fragmental elements is not that simple.

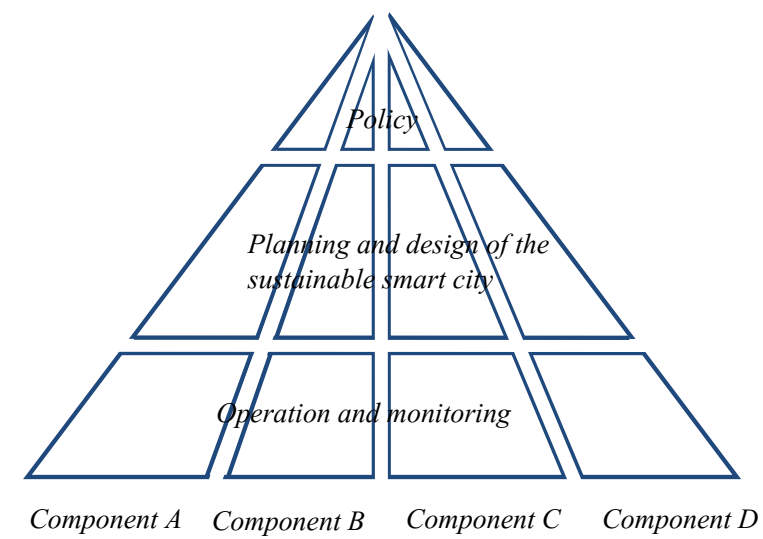

Fig. 3. The operational islands of the management of the smart city. Adapted from Kerzner, 2010 [14]

If we see an urban district as a functional system, it has similarities with an organization or a company. The operational islands model can be used to present the challenges that are faced by the managing of the fragmental elements of the smart city (Fig.3). The model is adapted from Kerzner's the operational islands model. It has different levels of hierarchy and different departments. Because of differences in the function and specialization, there are always functional gaps of 
different departments. Those factors lead to operational islands that individuals in their own island refuse to communicate with each other ${ }^{[14]}$. Under this point, one of the challenges of archiving a smart city is to build a connection between gaps and make individual islands communicate with each other in order to achieve common goals.

\section{Analysis and conclusions}

To conclude the theory study, in order to create a sustainable urban future, solar power as a clean energy resource can be a solution to lower the environmental impact and create a low carbon city. However, solar

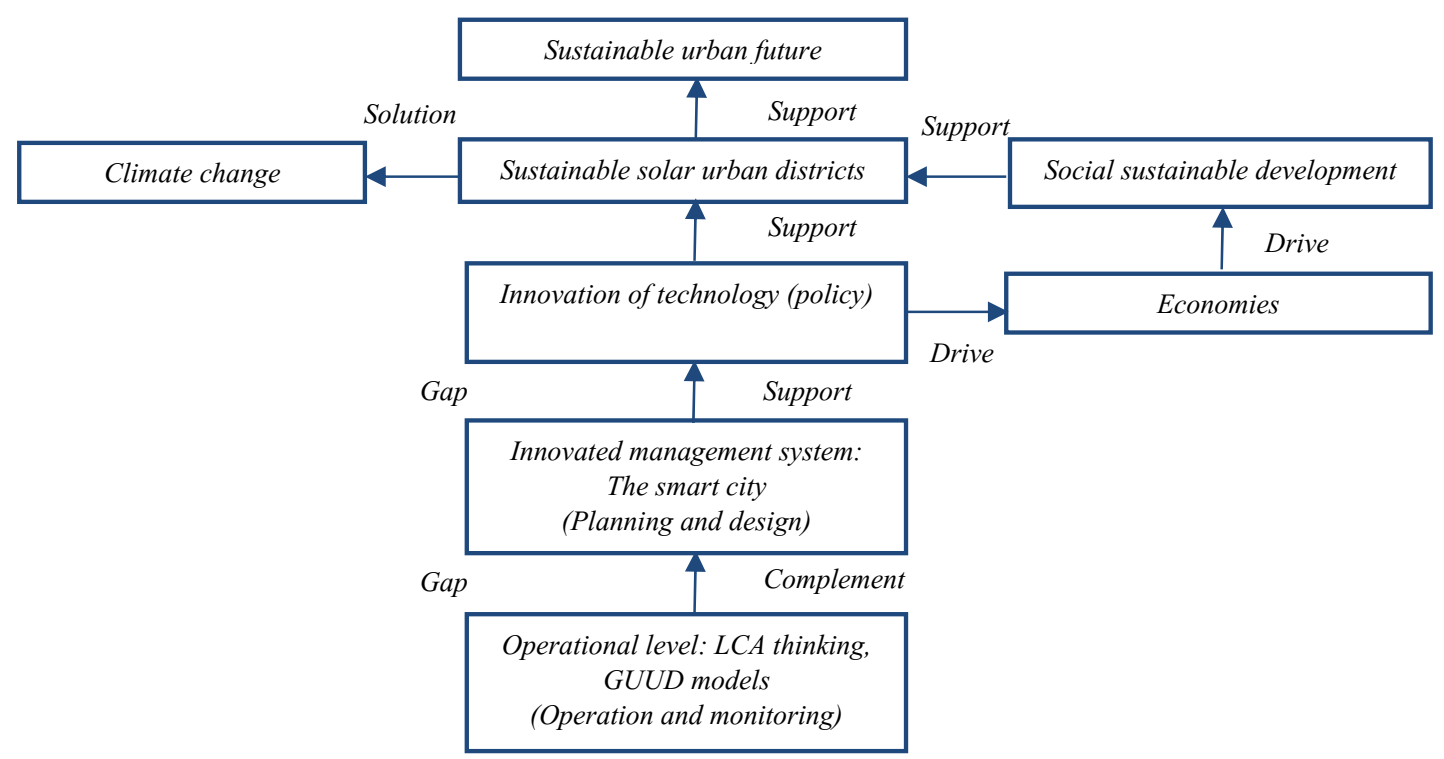

Fig. 4. The full structure of the theoretical study

power urban districts are facing challenges from both technology and social-economic side. In order to ignite the innovation of technology, innovation policy and management tools should be formed as a base to support innovation. Economic growth is driven by the innovation of technology; it also supports social sustainability. Economic and social development formed a foundation for a low carbon solar power city. In order to manage the multi-dimensional elements of the solar urban district, a smart city system as one innovative management system can be used. To manage the system from practical aspects, LCA thinking and GUUD models can be used. However, the fragmental elements are hard to manage. It is important to build a connection between functional departments (Fig.4).

\section{About the first author}

Jingxuan Zhang, Female, born in 1992, received her bachelor degree from VIA University College, Denmark, in Architecture Technology and Construction management in 2015. Then she received her master degree in Chalmers University of Technology, Sweden, in Design and Construction Project Management in 2017. Now she is currently working at Boya strategy,China, as design assistant. Her major interests include but not limited to architecture technology, BIM, sustainable development, social and ecological analysis of architecture and the building industry.

\section{References}

1. M. Amado, F. Poggi, Energy Procedia, Solar urban planning: A parametric approach, 48, 1539-1548, (2014)

2. J.R. Gil-Garcia, T. A. Pardo, T. Smarter as the New Urban Agenda, A comprehensive view of the 21st century city: Smartness as technologies and innovation in urban contexts, 11, 1-19. (2015)

3. United Nations. Transforming our world: The 2030 agenda for sustainable development, (2015)

4. J. Han, P. Fontanos, K. Fukushi, S. Herath, N. Heeren, V. Naso, C. Claudio, P. Edwards, K. Takeuchi, Sustainability Sci., Innovation for sustainability: toward a sustainable urban future in industrialized cities, 7, 91-100, (2012)

5. M. Amado, F. Poggi, Energy Procedia, Solar energy integration in urban planning: GUUD model, 50, 277-284, (2014)

6. BP Global, Solar energy, (2018), available on: https://www.bp.com/en/global/corporate/energyeconomics/statistical-review-of-worldenergy/renewable-energy/solar-energy.html

7. S. Kamp, Sveriges potential för elproduktion från takmonterade solceller, (2013) 
8. J. Rockström, Great Transition Initiative, Bounding the planetary future: Why we need a great transition, (2015)

9. European Commission. National/ Reginal Innovation Strategies for Smart Specialization (RIS3), (2014) Available on:

http://ec.europa.eu/regional_policy/sources/docgen er/informat/2014/smart specialisation_en.pdf

10. B. Monardo, Smart and Sustainable Planning for Cities and Regions, What Interpretations for 'Smart Specialization Strategies' in European Urban Regions? Lessons from Boston, 357-372, (2018)

11. K. G. Kim, Low-Carbon Smart Cities, Planning Models for Climate Resilient and Low-Carbon Smart Cities: An Urban Innovation for Sustainability, Efficiency, Circularity, Resiliency, and Connectivity Planning, 77-85, (2018)

12. European Commission, ILCD Handbook: Framework and requirements for life cycle impact assessment models and indicators, (2010)

13. PRé Sustainability, Handbook for Product Social Impact Assessment, 3, (2016) Available on:

https://product-social-impact-assessment.com/wpcontent/uploads/2014/07/Handbook-for-ProductSocial-Impact-Assessment-3.0.pdf

14. H. Kerzner, Project Management: A Project Management: A Systems Approach to Planning, Scheduling, and Controlling, 10th Edition, (2011) 